\title{
Primary energy congestion of power systems
}

\author{
Yusheng XUE ( $\bowtie)$, Bin CAI, Geoffrey JAMES, \\ Zhaoyang DONG, Fushuan WEN, Feng XUE
}

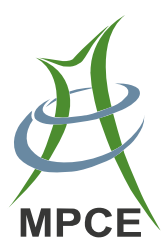

\begin{abstract}
Primary energy has the potential to bring challenges to the reliability, economic, and eco-friendliness of global electric power systems. The concept of electric power security are proposed, including many factors that are not considered in power system reliability analysis, such as coal supply for power system, fuel price for electricity power market, carbon emissions of power generation, and so on. It is broader than power system reliability and security, which means that providing energy in the form of reliable, economical, and eco-friendly electric power. Following an account of existing blackout defence methods and systems, the processes of transforming various kinds of primary energy into electric power and the interactions between them are described, particularly with regard to flows of energy, capital, and information. Factors that limit the liquidity of these flows are defined as "generalized congestion", and the challenges presented by primary energy are named "primary energy congestion". China's dilemma on coal supply for power generation is presented in some detail as an example of primary energy congestion. To cope with impacts of the primary energy on electric power systems, an idea is introduced to extend the scope of existing coordinated blackout defence systems to account for primary energy, which would lead to an
\end{abstract}

Received: 5 January 2013/Accepted: 1 June 2013/Published online: 15 October 2013

(C) The Author(s) 2013. This article is published with open access at Springerlink.com

Y. XUE, B. CAI, F. XUE, State Grid Electric Power Research Institute (SGEPRI), Nanjing 210003, China

$(\bowtie)$ e-mail: xueyusheng@ @gepri.sgcc.com.cn

B. CAI, Nanjing University of Science and Technology

(NJUST), Nanjing 210094, China

G. JAMES, Commonwealth Scientific and Industrial Research

Organisation (CSIRO), North Ryde, NSW 2113, Australia

Z. DONG, The University of Sydney, Sydney, NSW 2006,

Australia

F. WEN, Zhejiang University, Hangzhou 310027, China integrated tool to provide decision support to power system operators accounting for primary energy congestion.

Keywords Power system reliability, Energy security, Electric power security, Primary energy congestion, Blackout defence

\section{Introduction}

Beginning with the construction of the first thermal power plant in 1875 , modern power systems have become the largest and among the most complex man-made systems, supplying a global electricity consumption of 22,018 TWh in 2011 [1].

Power system reliability can be addressed by considering two basic functional aspects: adequacy and security [2]. Adequacy is the ability of the power system to supply the aggregate electric power and energy requirements of the customer at all times, taking into account scheduled and unscheduled outages of system components, without considering dynamic and steady-state stability. Security is the ability of the power system to withstand sudden disturbances such as electric short circuits or unanticipated loss of system components. Electric power engineers have researched how to achieve the power system reliability needed to deliver power to consumers within accepted standards and in the amount desired. The power system adequacy requirement is fulfilled by allocating and dispatching various kinds of reserve capacity. Security is a much more complex aspect of reliability. The 'August 14th, 2003' Blackout in North America demonstrated the importance of power system security and the need for an integrated defence framework [3].

The concept of "energy security" is widely used, yet an exact definition is hard to give as it has different meanings to different people $[4,5]$. This paper takes energy security 
to be "the uninterrupted physical availability at a price which is affordable, while respecting environment concerns" as defined by International Energy Agency [6]. In this paper, we address the issues of providing energy in the form of reliable, economical, and eco-friendly electric power, which are broader than power system reliability defined above. It includes many factors that are not considered in power system reliability analysis, such as coal supply for the power system, carbon emissions of power generation.

The provision of electric power requires a huge consumption of primary energy. However, research towards electric power security has so far been isolated from energy security. The time scale of power system adequacy (minutes to hours) and security (milliseconds to seconds) is far less than the storage time of fossil fuels or hydro reservoirs (days to months), so the security of the primary energy supply was not included in existing security analyses. Traditionally, the ability to supply primary energy was included in generation planning of power systems as a secondary factor, e.g. the production and transportation of power coal, but the impact of fluctuations in the supply chain and prices of coal were not significantly considered. Recently, reference [7] addressed this issue and proposed an integrated generation and transmission expansion planning model. It includes fuel availability limits at the fuel sources and the fuel transportation limits for the transportation of fuels from fuel sources to the generating unit locations.

Electric power demand in China has been growing fast along with the rapid economic growth. By the end of 2011, China became the country with the largest electricity consumption [8] and the largest scale of power grid in the world. This expansion of its power systems has been in part enabled by the upgrading of the blackout defence systems $[9,10]$.

Investment in renewable energy is an important part of China's strategy. The rapid growth of wind power capacity and the observed and expected impact on power system operations attract engineers' attention to the influence of wind energy, which is one kind of primary energy, on power system reliability [11]. Actually, all forms of primary energy have the potential to influence electric power security. For example, China has long been suffering from coal supply shortages for electricity generation caused by price and rail transportation capacity variations [12]. The national output of hydro-electricity decreased by $3.52 \%$ due to abnormally low precipitation, despite the construction of new dams to increase generation capacity by $6.69 \%$ in 2011 [8]. Reference [13] defines the factors that limit the liquidity of energy, capital, and information flows of power systems as "generalized congestion", which extends the concept of "transmission congestion". Natural events, rail congestion, market forces on prices, international politics, primary energy resource reserves, emission constraints, terrorist attacks, etc., can all be considered as generalized congestion. The challenges presented by primary energy will be named "primary energy congestion".

This is a global issue. Reference [14] discusses the integration of large amounts of intermittent renewable energy and its influence on power system reliability in several countries. Reference [15] estimates the climate vulnerability of Brazil's power system due to changing water resources and hydrology. South Australia achieved around $25 \%$ penetration of wind energy in 2011, which can expose the interconnectors to other states to excessive power flow variability, resulting in reduced effective capacity to export excess wind or to import balancing services [16]. In New England of the USA, the gas pipeline system was not designed to meet the growing natural gas generation demand, as most of these gas generators have not secured firm capacity on the pipeline system to gain needed supplies, which is a concern for energy reliability [17]. All of these examples demonstrate the primary energy challenge to global power systems.

Some issues of this challenge have been discussed. Reference [18] analyses the impact of natural gas infrastructure on electric power systems. Reference [19] proposes an integrated model for assessing the impact of interdependency of electricity and natural gas networks on power system security. Reference [20] presents a model for the supply/interconnections expansion planning of integrated electricity and natural gas. Reference [12] presents a "Macro Energy Perspective" to consider all the energy and other relevant fields (e.g. transportation) comprehensively in China, instead of considering them in isolation. However, a comprehensive framework for analysing the interaction between electric power and various kinds of primary energy resources, and developing ways for power systems to be defended against these challenges, does not yet exist. The ice disaster in China in 2008 made Chinese electric power engineers realize the importance of information about extreme disasters for power system, such as, ice rain, thunderstorms, snow disasters, typhoons, terrorist attacks, etc. An idea of extending the scope of defence systems to external natural disasters is presented in [21, 22]. Following this approach to extend the existing defence systems to primary energy fields could be a practical way to address these challenges, not only for China, but also for global power systems.

Hence, the present capabilities of blackout defence systems are reviewed in Section 2. Section 3 describes the significant position of electric power security for energy security. The interactions between power system and other energy systems are discussed in Section 4. Section 5 details the mechanisms and factors of primary energy 
congestion and analyses China's dilemma of coal supply for power generation as an instance of primary energy congestion. Some suggestions on coping with the challenges of primary energy within a blackout defence scheme are proposed in Section 6. All the data sources in this paper are publicly available materials.

\section{Blackout defence systems}

Towards comprehensive protection against primary energy congestion, the state of the art of power system security assessment and management must be firstly understood. A number of blackout defence frameworks for power systems have been established to cope with power system security in different countries or regions [23], including the United States, Europe, Russia [24], India [25], Canada [26], and Brazil [27]. A system that can successfully avoid extreme contingencies would reduce the need for operational constraints that reduce the risk of contingencies by operating the power system in a conservative manner [28]. Such operational constraints are very inefficient: the initial impact of unforeseen extreme contingencies is only a matter of minutes in any year, yet power flows can be restricted for hundreds of hours per year. A real-time, wide-area, adaptive protection and control system involving the power, communication, and computer infrastructures is proposed in [29].

The three-defence-line criterion has been a wellestablished security standard for power system planning and operation in China [30]. The first defence line consists of grid strengthening, preventative control (PC), and protection relays to ensure system stability without load interruption under a non-severe contingency. The second defence line is armed with remote emergency control (EC) for severe contingencies. The third defence line is equipped with local corrective control (CC) such as out-of-step islanding and load shedding for extremely severe contingencies. Although they have successfully prevented system-wide blackouts in the huge but relatively weak grids in China, these defence lines are facing great challenges in the new environment of rapid load growth, nation-wide interconnection, ultra-high voltage transmission and initial stages of power market development.

Integrating data from remote terminal units (RTUs), phase measurement units (PMUs), and a wide area measurement system (WAMS) enables a unified open platform of wide area information. This must be supported by considerable analytical power for state estimation and contingency analysis, to produce effective decision support and "situation awareness" for grid operators [31]. This information is coordinated and control actions are derived using supervisory control and data acquisition (SCADA) within the framework of an energy management system (EMS).

Taking the blackout defence system in China as an example, advanced features have been implemented for several years, including adaptive optimisation of PC, EC, and $\mathrm{CC}$, and coordinated optimisation of $\mathrm{PC}$ and $\mathrm{EC}$ [9]. The other key innovations are closed-loop adaptive additional EC for single-area fast cascading failures and multiarea concurrent failures, unified quantitative stability analysis using the extended equal area criterion (EEAC) [32], and adaptive contingency screening for dynamic identification for key factors of transient stability. These features are integrated in the wide area monitoring analysis protection-control (WARMAP) system [9] which is now deployed in 4/5 of China's grid. Jiangsu and Shanghai include all functions; Qinghai, Gansu, Yunnan, Guizhou, Hainan, and Jilin only include WAMS function; and the others include all functions except closed-loop EC. It operates at three levels, national, regional, and provincial, providing some autonomy within each level while exchanging data between all three. It has achieved a number of successful interventions. In July 2007 it provided decision support to prevent a cascading failure after a wind squall tripped two $500 \mathrm{kV}$ and three $220 \mathrm{kV}$ transmission lines from Taiwan nuclear power station. In May 2008 , it provided preventative control to ensure the stable operation of Sichuan Grid after it was substantially damaged by an earthquake. Eight times since December 2006, it provided timely early warning to dampen a low frequency oscillation in the Yunnan Grid.

This experience under real operating conditions is informing the next stage of development incorporating with Dynamic SCADA and Dynamic EMS, which are capable of synchronising data across the power system to millisecond accuracy and recording millisecond data to capture transient disturbances. This is also referred to as Synchrophasor technology [31]. Such detailed snapshots of the system state are used to realize on-line assessment of transient security and stability. A number of research challenges remain, for example, to extract forward trajectories directly from on-line PMU data rather than from simulations, which would be sufficiently fast to enable control applications based on dynamic assessment.

\section{Electric power security and energy security}

With continuous growth in total consumption and significant changes in energy mix, energy plays a very important role during the industrialization, urbanization, mechanization, and electrification of human society. 
Fossil fuels, traditionally include oil, coal, natural gas, which are the dominant energy resource representing $87.1 \%$ of the global total consumption in 2011 [1], are facing a lot of serious challenges, such as exhaustion, market fluctuations, and environmental congestion. Fossil fuel combustion accounts for about $90 \%$ of total global carbon dioxide $\left(\mathrm{CO}_{2}\right)$ emissions due to human activities [33]. The consumption of fossil fuels grew by $98 \%$, and $\mathrm{CO}_{2}$ emissions jumped by $86 \%$ from 1997 to 2009, in which the emissions from oil, gas, and coal increased by $35 \%, 157 \%$, and $129 \%$ respectively [34]. Emissions of greenhouse gases have driven the Earth's climate system dangerously outside of its normal range.

Non-fossil energy sources include nuclear, hydro, wind, solar, biomass, ocean energy and some other new energy sources, which are almost exclusively used for electric power excluding conventional biomass and biomass fuel. The global energy mix is diversifying with fast development of non-fossil energy sources, led by renewable energy. Despite the growing use of non-fossil energy sources, they still cannot meet the present growth rate of energy consumption, thus using these sources with increasing scale and efficiency is an inevitable trend in current energy and environmental situation. It is estimated that non-fossil energy sources could account for more than half of the growth of the power sector and make the power system cleaner [35].

Electric power security is a prominent component of energy security. The electric power industry accounts for $68 \%, 30 \%$, and $7 \%$ respectively of total coal, natural gas, and oil consumption, together making $33 \%$ of global fossil fuel consumption. After conversion and transmission losses, this provides more than $17 \%$ of end-use energy consumption [34], yet the electric power industry is responsible for around $40 \%$ of global $\mathrm{CO}_{2}$ emissions and is the biggest single source of emissions. This makes the transition to a low-carbon power system critical to enhancing the clean utilization of energy.

During the period 1991-2011, global electricity consumption grew by $81.9 \%$, substantially faster than the $51.4 \%$ growth of total primary energy consumption [1]. It is estimated that energy for power generation will continue to be the fastest growing sector, accounting for $57 \%$ of the projected growth in primary energy consumption to the year of 2030 [35]. Raising the global electrification level and encouraging people to use more electricity to meet their energy demand, along with improving the reliability, economy, and eco-friendliness of the power industry, is one of the important methods to ensure energy security. The feasibility of this trend comes from the characteristics of the power industry as follows.
1) Electric power, which is convenient to use, could be an ideal substitute for most other kinds of energy excluding some particular sectors, such as the dependence of aircraft on jet fuel. The progression of the technology will result in greater diffusion of various kinds of efficient electrical appliances, the use of electric power in industry, agriculture, commerce, and domestic sectors will be more extensive. This includes distributed generation, solar rooftops, replacing fossilfuel-fired household heating by electrical heat-pump equipment or district heating systems, electric vehicles and electric railways.

2) Interconnected power systems can lower electricity costs and emissions due to the higher energy efficiency of large power plants, which can consume the fossil fuels centrally and efficiently, while High and Ultra High Voltage (UHV) power transmission can transfer energy to consumption regions more efficiently and conveniently from distant coal mines as opposed to the railway transportation.

3) Power generation accounts for $94.8 \%$ of the total emissions from the power system, and the concentrated utilization of fossil fuels in large power plants is convenient for carbon capture and storage to reduce $\mathrm{CO}_{2}$ emissions.

4) The power system is an efficient carrier for using nonfossil fuel sources of energy, including nuclear, hydro, and other renewable sources, which is good for easing the dependence on fossil fuels and reducing emissions.

5) Some renewable sources are appropriate for dispersed supply of electrical energy, including wind turbines and solar PV systems, which can meet the energy and power demand of remote regions that are difficult or expensive to link to an interconnected power system. In such cases, local balancing resources must be available to match intermittent supply and variable demand.

6) The global generation mix for electric power is $40.6 \%$ from coal, $21.4 \%$ from natural gas, $5.1 \%$ from oil, $13.4 \%$ from nuclear fuel, $16.2 \%$ from hydroelectric generation, and $3.3 \%$ from other sources [34]. Countries are able to optimize their power generation mix according to the energy resources with which they are endowed, limiting the vulnerability of electric power security to circumstances of energy security. For instance, oil is often the focus of global attention on energy security, whereas only $5.1 \%$ of electric power is generated by oil, therefore oil security is not highly relevant to electric power security except through its impact on the prices of other primary fuels. Using a variety of primary energy sources for electricity generation also increases security, because generalised congestion of one source (for example, a period of low 
wind, or high fuel prices) can be compensated by another source.

7) The "smart grid" combines advances in power system operation, analysis and control technology, information technology, system planning, large-scale longdistance power transmission, integration of intermittent renewable energy, flexible application of microgrid, power and energy markets, in-depth participation of consumers, regulation, and investment regimes. This increases the flexibility of electricity systems to meet economic and environmental challenges.

\section{The complex interactions between power systems and other energy systems}

\subsection{Bidirectional upstream and downstream relationships}

On the one hand, generation of electric power is the downstream industry of other energy systems, e.g. oil, natural gas, and coal. Therefore, the reliability of electric power supply is limited by the stable supply of primary energy; the economy of electric power is relevant to the price of power generation fuels or development cost of renewable energy sources; and the environmental impact of electric power depends on the development of clean energy and the advanced low carbon technologies for combustion of fossil fuels. On the other hand, electric power security could affect the operation of other energy systems as the upstream industry to supply electric power to them, for instance, the electricity shortages in California affect almost all sectors of the state's economy, including crude oil and natural gas producers, petroleum refineries, and pipelines [36]. Hence, there exists a bidirectional upstream and downstream relationship between power systems and other energy systems with complex interactions within the process of energy flow. Electric power security should not be considered in isolation from the other energy systems.

\subsection{Processes of generating electric power from primary energy sources}

Power generation from various kinds of primary energy depends on several processes including mining, production, transportation, transformation, storage, and trade. To analyse mutual impacts, it is helpful to consider these processes in terms of the flows of three commodities, energy, capital, and information. The complexity of these flows individually, and the interactions among them, are shown in Fig. 1.
From the aspect of energy flow, uncertainties of the hydro resource and renewable energy and under-supply of nuclear and fossil fuels will cause power shortages. For example, Southeast China experienced the driest year on hydrological records in 2011, and coal-fired power plants did not produce sufficient electricity, which caused a critical power shortage in the South China Power Grid. Within transportation networks, various kinds of fuels could affect one another, for example, competition for railway transport capacity between coal and oil transportation, and the influence of large-scale hydroelectric power stations on water transportation for other fuels and cooling water for thermal power stations.

Besides, there exist interactions within the interconnected power system, which connects the electric generators driven by different energy sources. For instance, the allocation and dispatching rules of power system reserve capacity, usually provided by hydroelectric power or thermal power, have been changed by the integration of large amounts of intermittent renewable energy. This is an area of innovation in power system operations-for example, wind turbines with doubly fed induction generators (DIFG) can also provide reserve capacity for inertia and frequency support [37].

From the aspect of capital flow, all kinds of energy markets could affect one another, for example, the fluctuation of oil markets might affect the other energy markets and affect the stability of power market further, and investment in the rapid expansion of renewable energy industries could benefit from the substantial appreciation of prices of fossil fuels and the introduction of carbon pricing. From the aspect of information flow, energy markets rely on timely information being available to market participants, and the relationship between physical energy systems and energy markets is bound by the rules of economic dispatch under security constraints, all facilitated by complex information and computation. The information flows within energy markets and systems are not shown in Fig. 1.

\section{Mechanism of primary energy congestion and an example}

\subsection{Mechanism of primary energy congestion}

Primary energy supply is affected by many factors, such as proven reserves, market mechanisms, energy demand, weather and climate conditions, natural disasters, energy technology developments, transport infrastructure (railway, highway, and pipeline networks), the macroeconomic situation, policy and administrative 


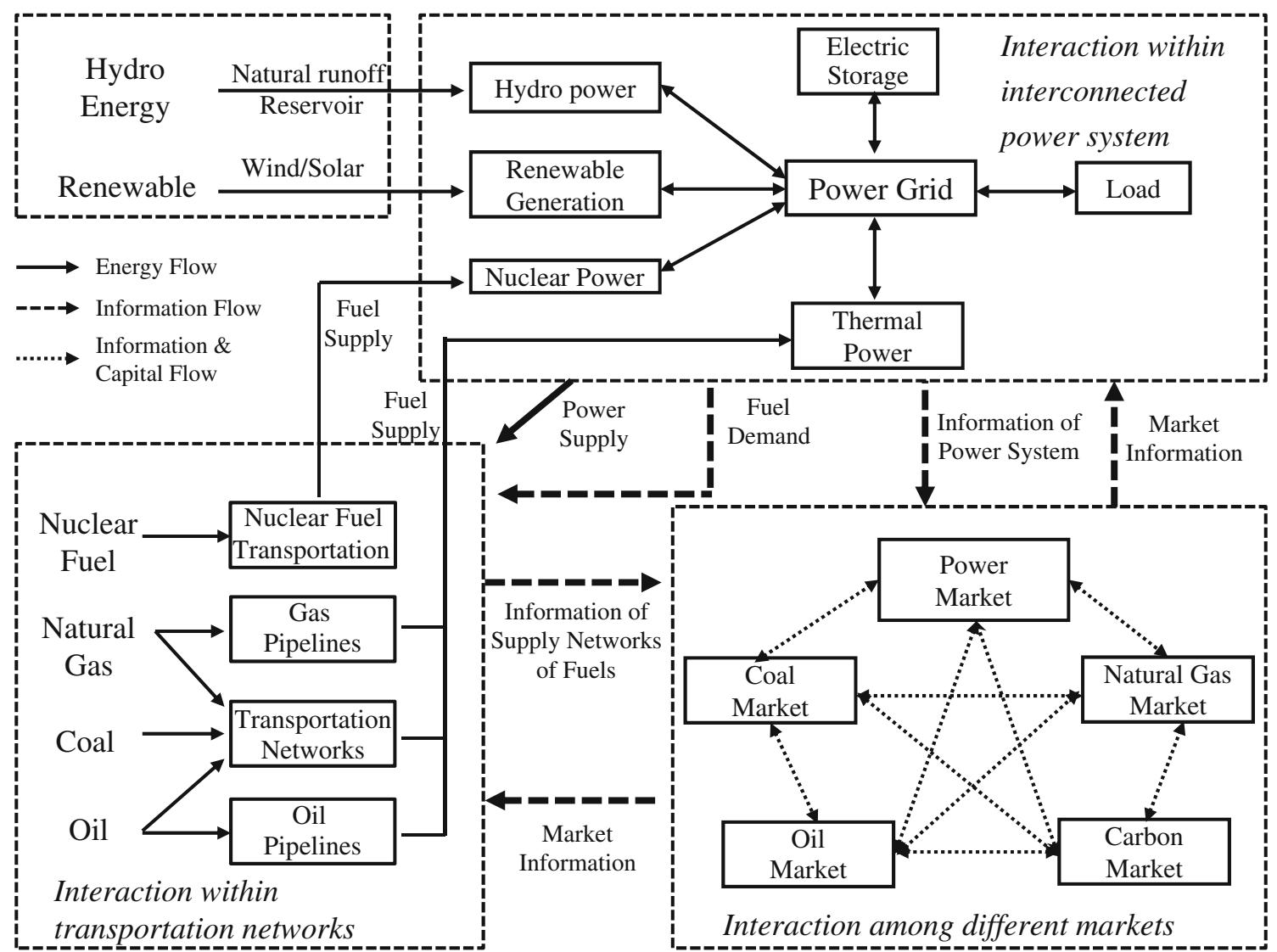

Fig. 1 The processes of generating electric power from various kinds of primary energy and the interactions among them

intervention, international trade and collaboration, the potential for terrorist attacks, acts of war, and so on. Fluctuations in primary energy supply caused by these factors could often give rise to output shortages from some power sources, which has a similar impact to power-system events such as load fluctuation and generator failure. The result can be uncontrollable blackouts if systems are faced with lack of reserve capacity and flexibility resources, or suffer from delayed emergency measures, or some other situations. Triggering mechanisms for different factors affecting primary energy and consequently the power system require specific understanding and formulation for each energy system. The mechanism by which primary energy congestion can cause a blackout is shown in Fig. 2.

Different factors and bottlenecks are found in the process of generating electric power from various kinds of primary energy. For instance, the biggest challenge for oil supply is the price fluctuation of global trade, whereas the major bottleneck for wind power is the natural variation of wind. The major factors influencing primary energy congestion of different fuels are shown in Table 1.

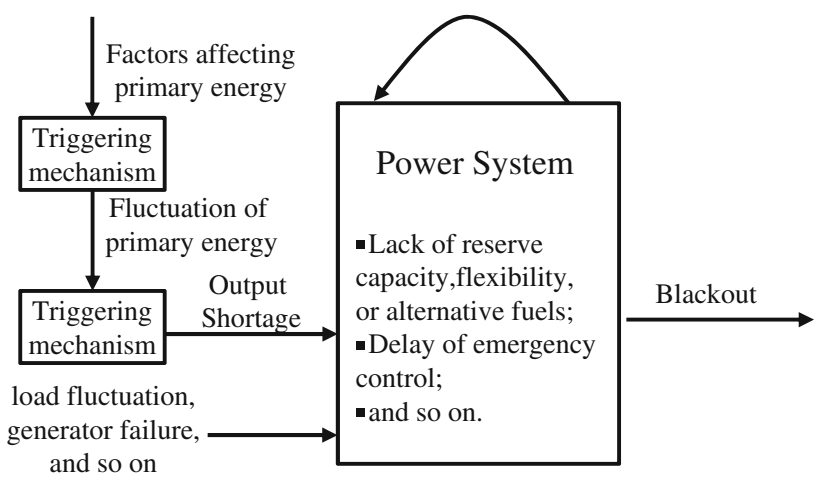

Fig. 2 The mechanism by which primary energy congestion can cause a blackout

\subsection{An instance of primary energy congestion: China's dilemma on coal supply for power generation}

Thermal power in China, which is $95 \%$ coal-fired, comprises $72 \%$ of the total installed capacity and, due to its generally high capacity factor, contributes $81 \%$ of total generated electrical energy [8]. Power generation accounts for nearly half of the annual coal consumption of China during the last 10 years [38]. China is rich in coal 
Table 1 Major factors of primary energy congestion

\begin{tabular}{|c|c|c|c|c|c|}
\hline & \multicolumn{2}{|l|}{ Fossil fuels } & \multicolumn{2}{|l|}{ Renewable } & \multirow[t]{2}{*}{ Nuclear } \\
\hline & Coal & Oil Natural gas & Hydro & Wind & \\
\hline Resource potential & \multicolumn{5}{|c|}{ Volumes of fuels are the primary basis of using them for generation } \\
\hline Transmission path & \multicolumn{2}{|c|}{$\begin{array}{l}\text { Railway, highway, water, and pipeline } \\
\text { transport }\end{array}$} & Natural runoff & $\begin{array}{l}\text { Natural air flow or } \\
\text { irradiation }\end{array}$ & $\begin{array}{l}\text { Special } \\
\text { transport }\end{array}$ \\
\hline Market trade & $\begin{array}{l}\text { International \& } \\
\text { domestic }\end{array}$ & $\begin{array}{l}\text { Global market } \\
\text { fluctuation }\end{array}$ & Value of stored energy & $\begin{array}{l}\text { Development of suitable } \\
\text { market mechanisms }\end{array}$ & Slight influence \\
\hline $\begin{array}{l}\text { Weather \& } \\
\text { climate }\end{array}$ & \multicolumn{2}{|l|}{ Slight influence } & Rely on rainfall & $\begin{array}{l}\text { Rely on air flow \& solar } \\
\text { irradiation }\end{array}$ & Slight influence \\
\hline $\begin{array}{l}\text { Other demand } \\
\text { sectors }\end{array}$ & \multicolumn{2}{|c|}{ Energy demand excluding power sector } & Shipping, water supply, etc. & - & - \\
\hline Environment & Emission constraints & $\begin{array}{l}\text { Relatively lower } \\
\text { emission }\end{array}$ & Water ecology constrain & - & Nuclear leakage \\
\hline Technology & \multicolumn{2}{|c|}{$\begin{array}{l}\text { Efficiency, carbon capture, carbon storage, } \\
\text { especially for coal }\end{array}$} & $\begin{array}{l}\text { Inflow forecast and reservoir } \\
\text { management }\end{array}$ & $\begin{array}{l}\text { Output forecast \& } \\
\text { system operation, etc. }\end{array}$ & Nuclear safety \\
\hline $\begin{array}{l}\text { Administration } \\
\text { and Politics }\end{array}$ & $\begin{array}{l}\text { Mechanism \& } \\
\text { intervention }\end{array}$ & $\begin{array}{l}\text { Trade restriction and } \\
\text { supply outage caused } \\
\text { by politics or war }\end{array}$ & Supporting or inhibiting & Supporting or inhibiting & $\begin{array}{l}\text { Supporting or } \\
\text { inhibiting }\end{array}$ \\
\hline Natural disaster & \multicolumn{5}{|c|}{$\begin{array}{l}\text { Natural disasters impact reliability of energy supply, such as a coal field damaged by flood, or nuclear leakage caused by } \\
\text { earthquake and tsunami }\end{array}$} \\
\hline
\end{tabular}

resources, with $13.3 \%$ of the world's total reserve [1], and many new coal reserves have been found in recent years [39]. However, this abundance is still insufficient, and the power industry in China is facing serious coal supply congestion due to supply and transport restrictions.

\subsubsection{Coal supply}

Domestic coal production cannot keep up with the demand. The coal demand in China has grown rapidly, along with the high rate of economic growth since 2001, causing the Chinese government to take measures to ensure domestic coal supply. The value added tax refund for coal exports was gradually abolished from 2004; the import tax on coal was gradually decreased and finally abolished to encourage coal imports from 2005. As a result, China became a net coal importer in 2009, and surpassed Japan as the biggest global importer in 2011 [40]. Under the assumption of China's average GDP growth rate of $8 \%$, it is estimated that the coal demand of China will keep increasing, whereas the coal production peak will occur between the late 2020s and the early 2030s. By 2030, the coal import dependence of China is projected to be about $23 \%$ under a low growth scenario and $45 \%$ in a high growth scenario, which means that about $50 \%$ of world's coal trade would be with China [41].

\subsubsection{Coal transport}

Coal supply to power stations is limited by shortage of coal transport capacity. China has large spatial disparities between coal reserves and consumption centres, driving the pattern of coal transportation to be "from North to South, and from West to East" by several transportation methods. The geographical scope of this pattern will be expanded. According to "China's 12th Five Year Plan for Coal" [42], Xinjiang, Gansu, Yunnan, Guizhou, and some other western provinces (or autonomous regions) with rich coal resources will increase their coal production to supply major regions of coal consumption, as shown in Fig. 3. Due to the advantages of high speed, large volume, low cost, and weather resistance, railway transport in China accounts for more than $60 \%$ of the total coal transportation. More than half of the railway network's total transport capacity, measured by tonnes transported, is required to provide this service [43] and the network has been overloaded for a long time.

The shortage of long distance electric power transmission capacity is another serious limitation. Coal-fired electric power and coal are two different energy forms in which to send coal energy from Shanxi, Shaanxi, and Inner Mongolia to other provinces, with the ratio of 1:20 [12]. Clearly there is an opportunity to increase the proportion of 


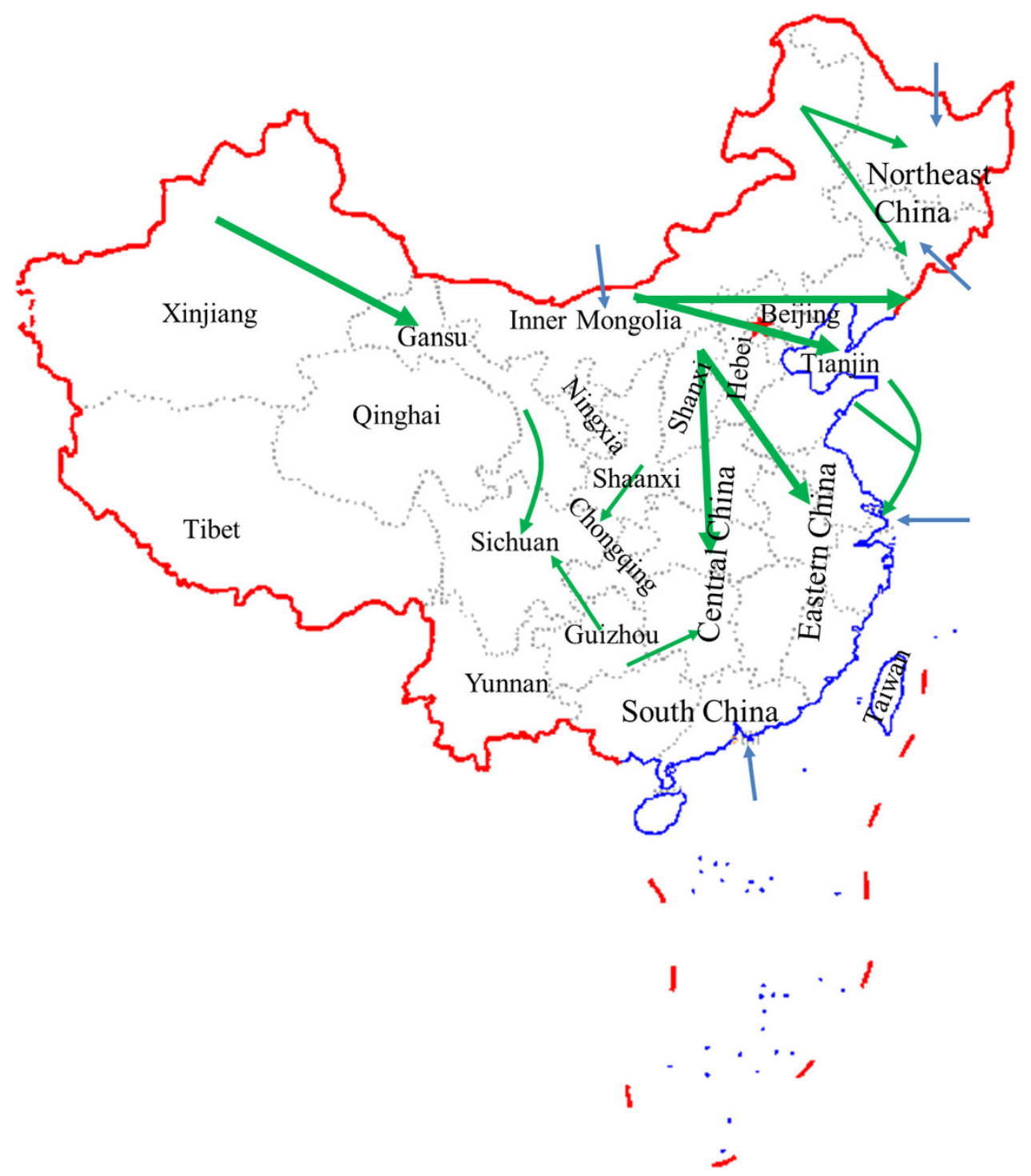

Fig. 3 Planned coal resource flows in China by the end of 2015, with domestic flows shown in green, and imports at ports and borders in blue [42]

coal energy transported as electrical power, as the highvoltage transmission network is developed. This suggests that power generation development should be harmonized with railway infrastructure and power transmission development in an optimal way, balancing coal transportation and power transmission. Such harmonization would also recognise that long-distance power transmission lines are also necessary for transferring China's future large-scale hydro, wind, and solar power from west to east [12].

\subsubsection{Price mechanisms}

Since the founding of P. R. China, the coal and electric power sectors have experienced imbalanced reform and development, forming a distorted price mechanism through the coexistence of "dual track of coal price" and "planned electricity price under regulation" $[44,45]$. On the one hand, the price gap of power coal between free market and major contract thermal coal reaches $20 \%-25 \%$, exceeding 200 Yuan per tonne, resulting in a decrease of the quantity and fulfilment rates of signed coal contracts [46]. On the other hand, the electricity price is regulated by government completely forming the only closed loop in the whole coalelectricity energy industry chain, which means growth in the coal price has not been reflected by a rising electricity price, leading to a financial deficit for generation companies. China's five largest State-owned power groups reported a total loss of 31.22 billion Yuan ( $\$ 4.96$ billion) for the thermal power sector in 2011, 19.07 billion Yuan more than that in 2010 [47]. As a consequence, the 
generation companies lose the motivation to generate electricity, and sometimes try to sell contract-purchased coal on the free market. In order to settle the resulting dispute between the coal and electricity industries, the government has tried to limit the coal price, raise the electricity price, and make the electricity price move together with the coal price. However, these open-loop measures are often time-delayed and ineffective, or hard to implement because of the difficulty in allocating the benefits between the two industries.

Recently, the price gap between the free market and major contracts for thermal coal started to narrow. Against this background, at the beginning of 2013, the government ended the "dual track of coal price" as the first step towards rationalising the price mechanisms of coal and electrical power. The effect of this reformation remains to be tested [48]. Furthermore, in the face of power shortages in recent years, the current consensus for action includes guaranteeing coal imports, improving the efficiency of coal mining, especially for township and village coalmines, releasing bottlenecks of coal transportation, and replacing the coal transportation with electrical power transmission.

\section{Extending the scope of the existing coordinated blackout defence scheme}

Electric power security relies on the security of primary energy supply, whereas, the production, transportation, control and some other aspects of other energy systems are affected by the electric power supply. Therefore, it is necessary to establish a "Macro Energy Perspective" to consider energy and other relevant fields comprehensively, instead of considering them in isolation [12].

Similar viewpoints were presented at "China's energy strategy and '12th Five-Year Plan' energy development forum: electric power sub-forum", which was held on June 19, 2010 [49]. Planning for electric power needs to be done in conjunction with planning for coal, transportation and other fields, as well as with overall energy, economic and social development planning. The relationship between the electric power industry and its up- and down-stream industries such as coal, oil and transportation is increasingly close, resulting in the necessity of enhancing the comprehensiveness and inclusiveness of power planning, and converting from the current closed system to an integrated platform for allocating energy and financial resources.

At present, China is boosting the development of smart grids, through a strategy of coordinated development of grids at different voltage levels, with UHV grids as its backbone. The blackout defence system described in Section 2 has an important role in maintaining system security

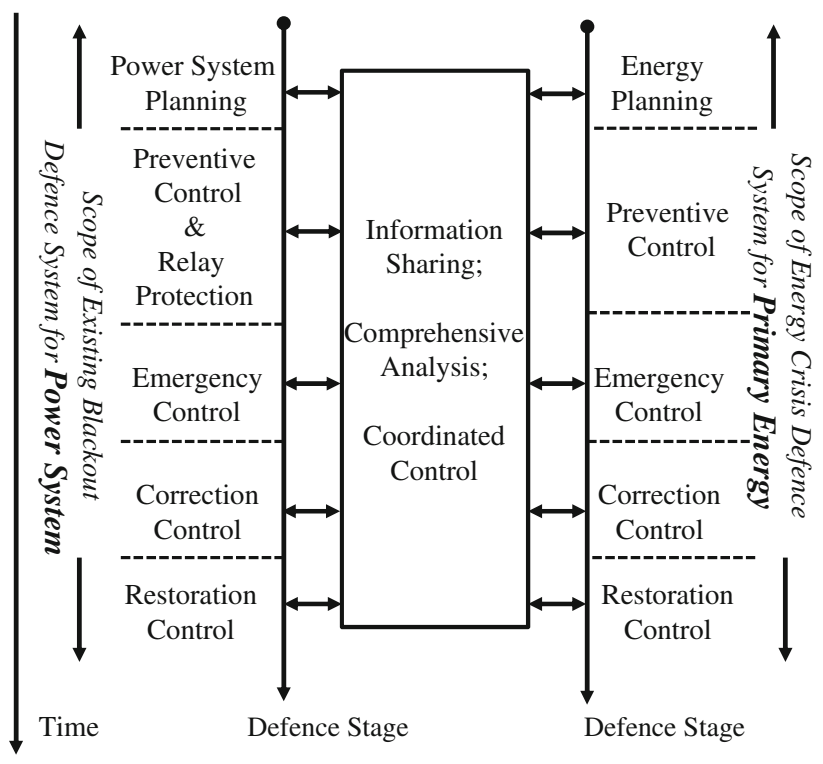

Fig. 4 Extending the scope of blackout defence schemes to include primary energy

during this period of expansion. Because primary energy congestion is also a challenge for the development of smart grids, further extending the existing blackout defence scheme to primary energy fields could produce an important tool to ensure both electric power security and energy security under the framework of generalized congestion. While the time scales for electric power and primary energy are often different, the method for approaching security through the three-defence-lines concept [9] can be applicable to both, and a common tool would permit the substantial impact of primary energy congestion on power system security to be addressed. Power system and primary energy defence systems should both perform information sharing, comprehensive analysis, and coordinated control. The necessary functions of a common tool, including information collection, risk analysis and alarm, crisis response plan making, and comprehensive analysis and coordination, shown in Fig. 4.

\section{Conclusion}

Electrical energy is playing an increasingly important role in secondary energy systems and supports the development of modern and prosperous societies. Electric power security relies on the stable supply of other forms of energy, and provision of electric power requires a huge consumption of primary energy. However, research towards electric power security has so far been isolated from energy security, which presents a risk to the provision of a stable power supply. Hence, this paper defines primary energy congestion as an extension of power system 
congestion, and proposes extending blackout defence systems to include the primary energy fields.

State-of-the-art blackout defence systems provide a suitable platform on which to address primary energy congestion. The interaction of coal supply, coal transport, and electricity generation and transmission in China provides an excellent example where an integrated defence tool would bring important benefits. Similar methodologies, based on the three-defence-lines concept used to address power system security, can be applied across the different timescales involved in primary energy and power system security. This suggests a research and development program that can be a major component of smart-grid development world-wide.

Acknowledgments This work is jointly supported by Major Program of National Natural Science Foundation of China (No. 91024028), National High Technology Research and Development Program of China (863 Program) (No. 2011AA05A105), SGCC Projects SGCC-MPLG003-2012, and the Australian Research Council (DP120101345).

Open Access This article is distributed under the terms of the Creative Commons Attribution License which permits any use, distribution, and reproduction in any medium, provided the original author(s) and the source are credited.

\section{References}

[1] BP statistical review of world energy June 2012. British Petroleum (BP), London (2012)

[2] Kundur P, Paserba J, Ajjarapu V et al (2004) Definition and classification of power system stability. IEEE Trans Power Syst 19(2):1387-1401

[3] Eto JH (2004) Blackout 2003: final report on the August 14, 2003 blackout in the United States and Canada: causes and recommendations. Electricity Markets and Policy Group, Energy Analysis and Environmental Impacts Department, US Department of Energy, Washington, DC

[4] Alhajji AF (2007) What is energy security? Definitions and concepts. Middle East Econ Surv 50(45):5

[5] Kruyt B, van Vuuren DP, de Vries HJM (2009) Indicators for energy security. Energy Policy 37:2166-2181

[6] Energy security. International Energy Agency (IEA), Paris (2012)

[7] Sharan I, Balasubramanian R (2012) Integrated generation and transmission expansion planning including power and fuel transportation constraints. Energy Policy 43:275-284

[8] Annual report on electricity regulation 2011. State Electricity Regulatory Commission of China (SERC), Beijing (in Chinese)

[9] Xue YS (2007) Towards space-time cooperative defence framework against blackouts in China. In: Proceedings of the IEEE Power Engineering Society general meeting, Tampa, FL, USA, 24-28 June 2007, p 6

[10] Xue YS (2008) Progresses of blackout defense systems in China. In: Proceedings of the IEEE Power and Energy Society general meeting, Pittsburgh, PA, USA, 20-24 July 2008, p 6

[11] Ackermann T, Kuwahata R (2011) Lessons learned from international wind integration studies. Energynautics $\mathrm{GmbH}$, Langen

[12] Liu ZY (2012) Electric power and energy in China. China Electric Power Press, Beijing (in Chinese)
[13] Xue YS, Li TR, Yin X et al (2010) A research framework for generalized congestions and market power. Autom Electr Power Syst 34(21):1-10 (in Chinese)

[14] Holttinen H, Meibom P, Orths A et al (2011) Impacts of large amounts of wind power on design and operation of power systems, results of IEA collaboration. Wind Energy 14(2):179-192

[15] Soitoa J, Freitasa M (2011) Amazon and the expansion of hydropower in Brazil: vulnerability, impacts and possibilities for adaptation to global climate change. Renew Sustain Energy Rev 15(6):3165-3177

[16] Wind power and wind farms in South Australia. http:// ramblingsdc.net/Australia/WindSA.html. Accessed 19 Nov 2012

[17] Challenges facing the natural gas and electric power interface in New England-and opportunities to improve mutual reliability. Northeast Gas Association, Needham Heights (2012)

[18] Shahidehpour M, Fu Y, Wiedman T (2005) Impact of natural gas infrastructure on electric power systems. Proc IEEE 93(5):1042-1059

[19] Li T, Eremia M, Shahidehpour M (2008) Interdependency of natural gas network and power system security. IEEE Trans Power Syst 23(4):1817-1824

[20] Unsihuay-Vila C, Marangon-Lima JW, de Souza ACZ et al (2010) A model to long-term, multiarea, multistage, and integrated expansion planning of electricity and natural gas systems. IEEE Trans Power Syst 25(2):1154-1168

[21] Xue YS, Fei SY, Bu FQ (2008) Upgrading the blackout defense scheme against extreme disasters: Part I New challenges and reflection. Autom Electr Power Syst 32(9):1-6 (in Chinese)

[22] Xue YS, Fei SY, Bu FQ (2008) Upgrading the blackout defense scheme against extreme disasters: Part II tasks and prospects. Autom Electr Power Syst 32(10):1-5 (in Chinese)

[23] Review of on-line dynamic security assessment tools and techniques. CIGRE WG C4.601. International Council on Large Electric Systems, Paris (2007)

[24] Makarov YV, Reshetov VI, Stroev VA (2005) Blackout prevention in the United States, Europe and Russia. Proc IEEE 93(11):1942-1955

[25] Mukhopadhyay S, Soonee SK, Narasimhan SR, et al (2008) An Indian experience of defense against blackouts and restoration mechanism followed. In: Proceedings of the IEEE Power and Energy Society general meeting-conversion and delivery of electrical energy in the 21 st century, Pittsburgh, PA, USA, 20-24 Jul 2008, p 7

[26] Trudel G, Bernard S, Scott G (1999) Hydro-Quebec's defence plan against extreme contingencies. IEEE Trans Power Syst 14(3):958-966

[27] Filho XV, Pilottto LAS, Martins N, et al (2001) Brazilian defense plan against extreme contingencies. In: Proceedings of the Power Engineering Society summer meeting. Vancover, Canada, 15-19 July 2007,vol 2, pp 834-839

[28] Lachs WR (2005) Area-wide system protection scheme against extreme contingencies. Proc IEEE 93(5):1004-1027

[29] Li H, Rosenwald GW, Jung JH et al (2005) Strategic power infrastructure defense. Proc IEEE 93(5):918-933

[30] DL 755-2001 Guide and standard of power system security and stability control, 2001 (in Chinese)

[31] Giri J, Parashar M, Trehern J, et al (2012) The situation room: control center analytics for enhanced situational awareness. IEEE Power Energy Mag 10(5):24-39

[32] Xue YS (1999) Quantitative study of general motion stability and an example on power system stability. Jiangsu Science and Technology Press, Nanjing (in Chinese)

[33] Olivier JGJ, Janssens-Maenhout G, Peters JAHW, et al (2011) Long-term trend in global $\mathrm{CO}_{2}$ emissions: 2011 report. PBL Netherlands Environmental Assessment Agency, Institute for Environment and Sustainability (IES) of the European Commission's JRC Joint Research Centre, Hague 
[34] Key world energy statistics. International Energy Agency (IEA), Paris (2011)

[35] BP energy outlook 2030. British Petroleum (BP), London (2012)

[36] Electricity shortage in California: issues for petroleum and natural gas supply. US Energy Information Administration (EIA), Washington, DC (2001)

[37] Gowaid IA, El-Zawawi A, El-Gammal M (2011) Improved inertia and frequency support from grid-connected DFIG wind farms. In: Proceedings of the power systems conference and exposition (PSCE'11), Phoenix, AZ, USA, 20-23 March 2011, p 6

[38] National Bureau of Statistics of China (NBS) (2011) China energy statistical yearbook 2011. China Statistics Press, Beijing (in Chinese)

[39] Communique on land and resources of China (2001-2010). Ministry of Land and Resources of China (MLR), Beijing (2001-2010) (in Chinese)

[40] China overtakes Japan as world's top coal importer. China Briefing, 26 Jan 2012

[41] Lin B, Liu J (2010) Estimating coal production peak and trends of coal imports in China. Energy Policy 38:512-519

[42] China's 12th Five Year Plan for coal. National Development and Reform Commission (NDRC), Beijing, 2012 (in Chinese)

[43] China coal transport capacity to reach 2 billion tonnes in 2011. http://www.ecoalchina.com/english/news/gnmtxw/967846.shtml. Accessed 9 Nov 2011 (in Chinese)

[44] Wang B (2007) An imbalanced development of coal and electricity industries in China. Energy Policy 35:4959-4968

[45] Peng WY (2011) Coal sector reform and its implications for the power sector in China. Resour Policy 36(1):60-71

[46] Contract negotiation between coal and electric companies will be held, stabilizing the coal price should be the focal point. http://energy.people.com.cn/GB/16290605.html. Accessed 11 Nov 2011 (in Chinese)

[47] Foreign power firm sheds assets. http://english.people.com.cn/ 90778/7811553.html . Accessed 9 May 2011

[48] General Office of the State Council of P. R. China. Guidance on deepening the reform of marketization of power coal. http:// www.gov.cn/zwgk/2012-12/25/content_2298187.html. Accessed 25 Dec 2012 (in Chinese)

[49] An outlook for power industry development strategy in "12th Five Year Plan". http://www.china5e.com/show.php?contentid $=135468$. Accessed 9 Oct 2010 (in Chinese)

Yusheng XUE received his Ph.D. degree in Electrical Engineering from the University of Liege (Belgium) in 1987. He became a Member of Chinese Academy of Engineering in 1995. He is now the Honorary President of State Grid Electric Power Research Institute (SGEPRI), State Grid Corporation of China. His research interests include nonlinear stability, control and power system automation.

Bin CAI received his B.S. degree in automation from Nanjing University of Science and Technology (NJUST), China, in 2007. He is currently a Ph.D. candidate in control theory at NJUST. He has been working in State Grid Electric Power Research Institute
(SGEPRI) as an industrial trainee since 2007. He joined the Commonwealth Scientific and Industrial Research Organisation (CSIRO), North Ryde, NSW, Australia, to pursue his Ph.D project sponsored by the China Scholarship Council (CSC) from 2011 to 2012. His research interests include power system adequacy and control, integrating renewable generation, electricity power market modelling and simulation, risk management.

Geoffrey JAMES received his Ph.D. degree for research in radioastronomy from the University of Tasmania, Tasmania, Australia, in 1991. He then joined the Commonwealth Scientific and Industrial Research Organisation (CSIRO), North Ryde, NSW, Australia, and worked on antennas for microwave communications. $\mathrm{He}$ is now a Principal Research Scientist in CSIRO's Energy Transformed flagship project. His research interests have evolved to include demand management, integrating renewable generation, distribution network evolution, transmission planning, and energy storage technology and applications. He is developing ChinaAustralia partnerships to assist progress towards clean and efficient power systems for the Asian region.

Zhaoyang DONG received Ph.D. from the University of Sydney, Australia, in 1999. He previously held academic positions at the University of Queensland, Brisbane, Australia, and industrial positions with Powerlink Queensland and Transend Networks, Australia. At the time of writing he was with the Department of Electrical Engineering, The Hong Kong Polytechnic University, Hong Kong, China. He is Ausgrid Chair in Intelligent Electricity Networks at the University of Newcastle, Australia. His research interest includes power system security assessment and enhancement, power system planning, electricity market, computational intelligence and its application in power engineering, and smart grid.

Fushuan WEN received his Ph.D. degree in electrical engineering from Zhejiang University, China, in 1991. He joined the faculty of Zhejiang University in 1991, and has been a full Professor and the Director of the Institute of Power Economics and Information since 1997, and the Director of Zhejiang University-Insigma Joint Research Center for Smart Grids since 2010. He had been a University Distinguished Professor, the Deputy Dean of the School of Electrical Engineering and the Director of the Institute of Power Economics and Electricity Markets in South China University of Technology (SCUT), China, from 2005 to 2009. His current research interests lie in power industry restructuring, power system alarm processing, fault diagnosis and restoration strategies, as well as smart grids.

Feng XUE received his Ph.D. degree from University of Bath, UK in 2008 and is now working with the State Grid Electric Power Research Institute (SGEPRI), Nanjing, China. He is now the Deputy Director of SGEPRI's Power System Stability Control Company. He is an IEEE senior member and IET member. His major research field is focused on the analysis and control of power system stability. 